\title{
Determination of glyphosate herbicide and aminomethylphosphonic acid in natural waters by liquid chromatography using pre-column fluorogenic labeling. Part I: Direct determination at the $0.1 \mu \mathrm{g} / \mathrm{L}$ level using FMOC
}

\author{
E. Le Fur ${ }^{1}$, R. Colin ${ }^{1,2}$, C. Charrêteur ${ }^{*}$, C. Dufau ${ }^{2}$, J.-J. Péron ${ }^{2}$ \\ ${ }^{1}$ Centre de Génie Industriel, Guidel-plages, F-56520 Guidel, France \\ ${ }^{2}$ Laboratoire de Biologie et Chimie Moléculaires, Université de Bretagne Sud, rue Saint Maudé, \\ F-56325 Lorient, France
}

\begin{abstract}
An analytical method has been developed for the determination of glyphosate herbicide and its metabolite aminomethylphosphonic acid (AMPA) in natural waters to a level of $0.10 \mu \mathrm{g} / \mathrm{L}$ with a good linearity in the range $0.10-2.00 \mu \mathrm{g} / \mathrm{L}$ and coefficients of variation under $20 \%$ for each spiked level. The procedure involves a precolumn derivatization step with 9-fluorenylmethylchloroformate (FMOC-Cl) yielding highly fluorescent derivatives of the analytes which then can be determined by HPLC with fluorescence detection. The method is used for analysis of natural (surface and ground) and treated waters. Matrice effects have been pointed out, particularly the effects of hard ionic content and the effects of chlorine residues into treated waters.
\end{abstract}

Keywords. Glyphosate - AMPA - HPLC - fluorescence - FMOC.

\section{Introduction}

A substantial number of pesticides are still very difficult to analyse in water at the $0.10 \mu \mathrm{g} / \mathrm{L}$ level, the maximum allowable concentration for the quality of water intended for human consumption set by the European Union. Among them are the widely used polar non-selective glyphosate herbicide and its major degradation product AMPA.

Several chromatographic methods have been developed for the analysis of glyphosate and AMPA. Methods involving liquid chromatography seem to give better results since glyphosate and AMPA are very polar compounds. The nature of chromatographic phase depends on the detection mode selected. For instance, ionic phases are combined with conductimetric detection [1], mass spectrometry detection [2,3], UV or fluorescence after post-column derivatization with OPA [4], ninhydrin [5,6,7] or $\mathrm{Al}^{3+}$-morin reagent [8]. With a precolumn derivatization with 9-fluorenylmethylchloroformate (FMOC-Cl) for instance, reversed phase column may be used before fluorescence or UV detection.

A pre-concentration of sample is necessary to reach the limit of quantification of $0.10 \mu \mathrm{g} / \mathrm{L}$. Without any pre-concentration, the best performances were obtained by LC-MS analysis with a limit of detection (L.D.) of $1.00 \mu \mathrm{g} / \mathrm{L}$ [2] and by LC-fluorescence after FMOC derivatization with a L.D. of $0.40 \mu \mathrm{g} / \mathrm{L}$ [9].

The aim of this study was to reach a limit of quantification lower than $0.10 \mu \mathrm{g} / \mathrm{L}$ without any pre-concentration or purification of samples before analysis. The work was oriented along two ways:

1. Improvement of a published method involving LCFluorescence analysis after pre-column FMOC derivatization for direct determination of glyphosate and AMPA in water samples at the $0.10 \mu \mathrm{g} / \mathrm{L}$ level that is suitable for monitoring purposes (part I). This choice is explained below.

2. Development of a new method based on derivatization of glyphosate and AMPA with fluorogenic reagents. The first results of this work are presented in part II with 4chloro-7-nitrobenzofurazan reagent.

Among the methods described in literature for the analysis of glyphosate and AMPA in water by liquid chromatography, the way of pre-column derivatization along with fluorescence detection was selected because its easy use. Few coupling reagents have been tested: dansyl chloride [10], ptoluenesulfonyl chloride [11,12], phenylisothiocyanate [13]

*Correspondence and reprints.

Received July 6, 2000; revised September 12, 2000; accepted September 19, 2000. 


\section{Original articles}

or 9-fluorenylmethylchloroformate (FMOC-Cl) [9, 14-17]; the last one gave the best results.

Preliminary tests were carried out to value the ability of reaching a limit of quantification of $0.10 \mu \mathrm{g} / \mathrm{L}$ by direct analysis of pure water sample derivatized by FMOC. They showed that the fixed limit was accessible using a high performance fluorometer.

This paper describes the development of the method, results of validation and a study of matrix effects and interference using standard implementations.

\section{Experimental}

\section{Reagents}

Water solutions of glyphosate and AMPA (10 mg/L) were obtained from Dr. Ehrenstorfer GmbH (Germany). Acetonitrile and diethyl ether, both of HPLC grade were purchased from Carlo Erba (France). Analytical-reagent grade potassium dihydrogenphosphate, disodium tetraborate decahydrate, potassium hydroxide, phosphoric acid, $\mathrm{Na}_{2}$ EDTA were bought from Carlo Erba (France). FMOC$\mathrm{Cl}$ was obtained from Aldrich (France). Purified water was obtained from a Aqualyse system (Purit France). Sodium thiosulfate $20 \mathrm{mg}$ pellets were obtained from Flandre Chimie (France).

Stock standard solutions of glyphosate and AMPA at $30 \mu \mathrm{g} / \mathrm{L}$ were prepared in pure water.

0.1 M EDTA was used for pre-treatment of samples. $0.05 \mathrm{M}$ tetraborate buffer, $\mathrm{KOH} 3 \mathrm{M}, \mathrm{KH}_{2} \mathrm{PO}_{4} 0.1 \mathrm{M} \mathrm{pH} 2$ buffer in purified water as well as $1 \mathrm{~g} / \mathrm{L}$ solution of FMOC$\mathrm{Cl}$ in acetonitrile were used to perform derivatization.

Mobile phase 1: Acetonitrile/0.03 $\mathrm{M} \mathrm{K \textrm {KH } _ { 2 }} \mathrm{PO}_{4}$ (pH 5.75) in water $(45: 55 \mathrm{v} / \mathrm{v})$.

Mobile phase 2: Acetonitrile/0.05 $\mathrm{M} \mathrm{KH}_{2} \mathrm{PO}_{4}(\mathrm{pH} 5.75)$ in water $(30: 70 \mathrm{v} / \mathrm{v})$.

The $\mathrm{pH}$ of the aqueous buffer solution was adjusted with $\mathrm{KOH}$ solution.

\section{Apparatus}

HPLC System: The LC-Fluorescence detection system consisted of a Dynamax sampler (Rainin) equiped with a $50 \mu \mathrm{L}$ loop, a Varian Model 9012 LC gradient pump, a Jasco Model FP-1520 spectrofluorometer set at $260 \mathrm{~nm}$ (excitation) and $310 \mathrm{~nm}$ (emission).

The Supelco APS-1 $5 \mu \mathrm{m}$ column $250 \times 3.2 \mathrm{~mm}$ ID or the Macherey-Nagel $\mathrm{NH}_{2} 5 \mu \mathrm{m}$ column $250 \times 3 \mathrm{~mm}$ ID were kept at $30{ }^{\circ} \mathrm{C}$ in a Croco-Cil column heater (Cluzeau). The flow rates were set at 0.5 and $0.42 \mathrm{~mL} / \mathrm{min}$ respectively.

Recording of chromatograms and measurements of peak areas were performed with a Borwin acquisition station.

\section{Sample preparation}

\section{Procedure 1}

$0.5 \mathrm{~mL}$ of tetraborate buffer, $0.5 \mathrm{~mL}$ of FMOC solution and $0.5 \mathrm{~mL}$ of acetonitrile are added to $3 \mathrm{~mL}$ of sample.

After 30 minutes of reaction at room temperature, the solution is washed one time with diethylether $(50 / 50 \mathrm{v} / \mathrm{v})$.

After 1 hour of decantation, the aqueous phase is transferred into a vial for analysis.

\section{Procedure 2}

$0.5 \mathrm{~mL}$ of tetraborate buffer is added to $3 \mathrm{~mL}$ of sample.

After 15 minutes, this solution is washed one time with diethylether $(50 / 50 \mathrm{v} / \mathrm{v})$.

After 15 minutes, $1.5 \mathrm{~mL}$ of aqueous phase is pipetted and $250 \mu \mathrm{L}$ of FMOC solution as well as $250 \mu \mathrm{L}$ of acetonitrile are added.

Steps 2 and 3 of procedure 1.

\section{Procedure 3}

Identical to procedure 2 except that the aqueous phase is acidified with $140 \mu \mathrm{L}$ of phosphate buffer $\mathrm{pH} 2$ before the second wash step.

\section{Sample analysis}

Procedures 1 and 2 were associated with chromatographic analysis on amino column with mobile phase 1 .

Procedure 3 was associated with chromatographic analysis on amino column with mobile phase 2 .

Two ways of calibration were tested: a spiked levels method (two levels of implementation at 0.5 and $1.0 \mu \mathrm{g} / \mathrm{L}$ ) and an external calibration method.

\section{Results and discussion}

For the separation of derivatized glyphosate, we first tested a C18 column. This column showed short retention time for polar compounds and presented the advantage of not eluting the excess of FMOC-Cl during several injections. An unstable glyphosate retention time and a bad linearity in the range $0.10-1.00 \mu \mathrm{g} / \mathrm{L}$ were observed. Moreover, the selectivity was poor and the analysis of raw water samples provided unsatisfactory results because of numerous interferences.

In a second way, the use of an amino column was decided despite the instability and rapid deterioration of this stationary phase when using aqueous eluant. The retention time of glyphosate decreased $30 \%$ after 150 injections. We noticed a large variety in the quality of amino columns depending on the provider. The columns directly conditioned into reversed phase were better than classical column conditioned in normal phase. An improvement of sensitivity was 
observed when using $3 \mathrm{~mm}$ ID column compare to 4.6 ID column. The $3 \mathrm{~mm}$ ID column also permitted to divide twice the injection volume which led of course to a better resolution.

\section{Glyphosate}

\section{Sample preparation}

The conditions of glyphosate derivatization by FMOC were established from a study of the methods described in literature [9,14-17]. Amounts of different components were optimised as well as the time of reaction for spiked pure water samples. We found the best results with the proportions of sample, borate buffer and FMOC solution given in procedure 1. The optimum time of reaction was 30 minutes (no significant improvement of reaction yield over 30 minutes). Different solvents were tested for their ability to remove excess reagent from the solution. Diethylether gave better results (efficiency + decantation facilities) than $\mathrm{CH}_{2} \mathrm{Cl}_{2}$ propanol (2:1) [14], ethylacetate [15] or pentane. Derivatized samples were found to be stable for 15 days at $-18{ }^{\circ} \mathrm{C}$.

\section{Interference study}

This procedure of analysis was applied on the drinking water of our laboratory. The results showed in table I revealed a lower sensitivity than in purified water (the slope was divided twice). An effect of the matrix on the performances of analysis was pointed out. To correct this effect, a washing step of basified sample by diethylether was introduced (procedure 2). Interference due to organic matter, and particularly amino compounds, was eliminated as shown by the recovery results (Tab. I).

Moreover, we observed that chlorine residues of treated waters could oxidise spiked amounts of glyphosate and AMPA leading to zero or low slopes. A pre-treatment step consisting in addition of sodium thiosulfate pellet to the sample (1 pellet per litre of sample), was added in the preparation of treated waters samples in order to inhibit chlorine action.

The complete validation of procedure 2 was carried out on pure water in accordance with the experimental AFNOR standard NF XP T90-210 (Testing waters - Procedure for the evaluation of an alternative quantitative physicochemical analysis method against a reference method). The statistical indicated a good linearity in the range $0.10-2.00 \mu \mathrm{g} / \mathrm{L}$. The coefficient of variation (CV) was under $20 \%$ for each spiked level. The limits of detection and quantification were calculated from blanks analysis to be $0.04 \mu \mathrm{g} / \mathrm{L}$ and $0.06 \mu \mathrm{g} / \mathrm{L}$ respectively (Tab. II).

The specificity of the method was studied toward treated water and untreated river waters. For treated water, good recovery levels of $102-118 \%$ were calculated from the analysis of 4 samples at five spiked levels. The calibration curve estimated by linear regression was not significantly different from that obtained on pure water. For untreated river waters, the results (Tab. III) showed a homogeneity of
Tab. I. Glyphosate - Results of reproducibility obtained on treated waters (2 spiked levels). Conditions: Supelco APS-1 column, mobile phase 1 .

\begin{tabular}{lcrr}
\hline Sample & $\begin{array}{c}\text { Procedure of sample } \\
\text { preparation }\end{array}$ & Slope & $\begin{array}{c}\text { Recovery } \\
(\%)\end{array}$ \\
\hline Pure water & 1 & 1099856 & 100 \\
laboratory drinking water & 1 & 496771 & 45 \\
laboratory drinking water & 2 & 892332 & 82 \\
laboratory drinking water & 2 & 961443 & 88 \\
laboratory drinking water & 2 & 1040989 & 95 \\
laboratory drinking water & 2 & 953449 & 87 \\
\hline
\end{tabular}

Tab. II. Glyphosate - Results of repeatability obtained on spiked pure water. Conditions: Supelco APS-1 column, mobile phase 1, procedure 2 of sample preparation.

\begin{tabular}{ccc}
\hline $\begin{array}{c}\text { Spiked level } \\
(\mu \mathrm{g} / \mathrm{L})\end{array}$ & $\begin{array}{c}\text { Mean area } \\
\text { (10 replicates })\end{array}$ & $\begin{array}{c}\text { Coeff. of } \\
\text { variation }(\%)\end{array}$ \\
\hline 0.0 & 22141 & 16.37 \\
0.1 & 116003 & 8.55 \\
0.5 & 473170 & 6.49 \\
1 & 837013 & 8.22 \\
1.5 & 1434478 & 17.12 \\
2 & 1824377 & 7.04 \\
\hline
\end{tabular}

Slope: 912880 ; intercept: 5870

slopes and indicated that there was no matrix effects. The method was specific for the all types of water submitted to analysis in our laboratory.

However, two low slopes were recorded for Seine river waters. It was suggested that derivatization of glyphosate by FMOC could be affected by divalent ions such as copper, calcium or magnesium. In order to confirm this hypothesis, the analysis of two different mineral waters were compared (Fig. 1). The main differences between these waters are their hardness (5.0 french degrees for Volvic versus 29.4 french degree for Evian), their conductivity $(190 \mu \mathrm{S} / \mathrm{cm}$ for Volvic versus $580 \mu \mathrm{S} / \mathrm{cm}$ for Evian) and the content in bicarbonate (65.3 for Volvic versus $357 \mathrm{mg}$ for Evian). The curves clearly showed a worse sensitivity for the second mineral water. It was concluded that interference occurred too for mineralised waters. This behaviour could be compared to the sensitivity of fluorogenic reagents toward divalent ions in the amino-acid coupling [18]. To correct this effect, samples may be pre-treated with EDTA $0.1 \mathrm{M}(10 \mathrm{~mL}$ for 1 litre of sample). However, the different experiments carried out gave bad results.

\section{Proposed method}

For routine analysis, the chromatographists of our laboratory then used procedure 2 with two spiked levels at 0.5 and $1.0 \mu \mathrm{g} / \mathrm{L}$. The slopes and values obtained for standards and river waters during 2 months are presented in table IV. The 


\section{Original articles}

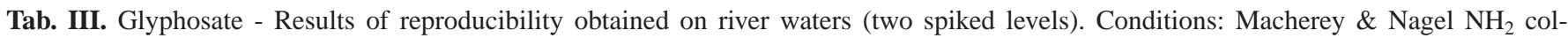
umn, mobile phase 1 , procedure 2 of sample preparation.

\begin{tabular}{lccc}
\hline Sample & Concentration $(\mu \mathrm{g} / \mathrm{L})$ & slope & Coeff. of correlation \\
\hline River water 1 & $<$ limit of quantification & 1091715 & 0.986 \\
River water 2 & 0.1 & 997751 & 0.995 \\
River water 3 & $<$ limit of quantification & 1176388 & 0.998 \\
River water 4 $-1^{\text {st }}$ sample & $<$ limit of quantification & 1266016 & 0.990 \\
River water 4 $-2^{\text {nd }}$ sample & 0.05 & 1057426 & 0.999 \\
River water 5 & 0.08 & 991787 & 1.000 \\
River water 6 & $<$ limit of quantification & 887512 & 0.997 \\
River water 7 & $<$ limit of quantification & 865215 & 0.994 \\
& & Mean: 1041726 & \\
River water A & CV (\%): 13.1 & 0.992 \\
River water B & 583755 & 0.991 \\
\hline
\end{tabular}

Rivers 1 to 7 are located in Brittany (France). Rivers A and B are two points located on Seine (France).

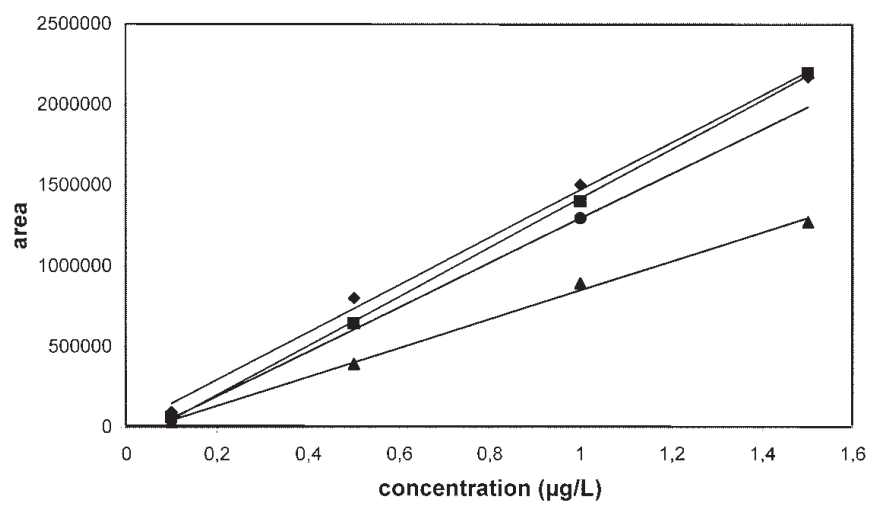

Figure 1. Effect of hardness on glyphosate analysis. Comparison between pure water $(\bullet)$, treated water $(\square)$, Evian mineral water $(\boldsymbol{\Delta})$ and Volvic mineral water $(\bullet)$. Conditions: Macherey\&Nagel $\mathrm{NH}_{2}$ column, mobile phase 2 , procedure 3 of sample preparation.

homogeneity of slope values led us to conclude on the robustness of our method. These results brought us to envisage an external standard calibration except for the analysis of some highly hard natural waters.

\section{Procedure extended to AMPA analysis}

In order to introduce the metabolite AMPA in this analytical method, we diminished the strength of mobile phase by lowering the percentage of acetonitrile (45 to $30 \%$ ). The resulting increase of retention time of glyphosate was compensated by an increase in phosphate buffer concentration $(0.03$ to $0.05 \mathrm{M})$. A typical chromatogram is shown in figure 2. In these conditions, elution of AMPA and glyphosate occurred at 7.5 and 23 minutes respectively. However, retention time of AMPA corresponded to the end of FMOC peak and the quantification was consequently difficult. An

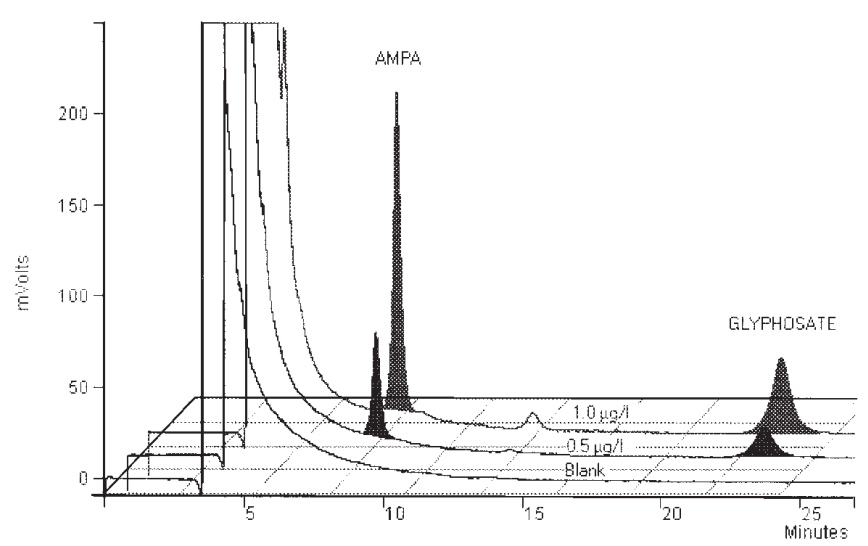

Figure 2. Chromatograms of standards at $0,0.5$ and $1.0 \mu \mathrm{g} / \mathrm{L}$. Conditions: Macherey\&Nagel $\mathrm{NH}_{2}$ column, mobile phase 2, procedure 3 of sample preparation.

Tab. IV. Glyphosate - Results of reproducibility obtained on standards (two spiked levels). Conditions: Macherey \& Nagel $\mathrm{NH}_{2}$ column, mobile phase 1 , procedure 2 of sample preparation.

\begin{tabular}{lcc}
\hline sample & $\begin{array}{c}\text { Mean slope } \\
\text { (number of samples) }\end{array}$ & $\begin{array}{c}\text { Coeff. of } \\
\text { variation (\%) }\end{array}$ \\
\hline $\begin{array}{l}\text { standard } \\
\text { River waters } \\
\text { (14 different rivers) }\end{array}$ & $1109853(10)$ & 18.4 \\
\hline
\end{tabular}

improvement of elimination of excess of FMOC reagent was necessary. This was accomplished by lowering the $\mathrm{pH}$ of the solution before the second wash by diethyl ether. The $\mathrm{pH}$ was selected in order to eliminate FMOC excess without any loss of glyphosate or AMPA derivatized. In this way, $\mathrm{pH} 2$ to 9 were tested. The optimum $\mathrm{pH}$ was found to be 5 . 
Tab. V. Glyphosate, AMPA - Results of repeatability obtained on pure water. Conditions: Macherey\&Nagel $\mathrm{NH}_{2}$ column, mobile phase 2, procedure 3 of sample preparation.

\begin{tabular}{|c|c|c|c|c|}
\hline substance & Concentration $(\mu g / L)$ & Mean area ( 7 replicates) & Coeff. of variation (\%) & calibration \\
\hline glyphosate & 0.0993 & 181944 & 10.8 & area $=1013683 *$ conc.+93240 \\
\hline \multirow[t]{4}{*}{$\mathrm{R}^{2}=0.9925$} & 0.2459 & 333549 & 3.6 & \\
\hline & 0.5000 & 680049 & 14.4 & \\
\hline & 0.9470 & 970503 & 3.0 & \\
\hline & 1.7647 & 1905728 & 0.6 & \\
\hline AMPA & 0.0993 & 192471 & 8.0 & area $=2440704 *$ conc.-70036 \\
\hline \multirow[t]{4}{*}{$\mathrm{R}^{2}=0.9999$} & 0.2459 & 519925 & 3.2 & \\
\hline & 0.5000 & 1126484 & 2.0 & \\
\hline & 0.9470 & 2256102 & 1.3 & \\
\hline & 1.7647 & 4236179 & 1.0 & \\
\hline
\end{tabular}
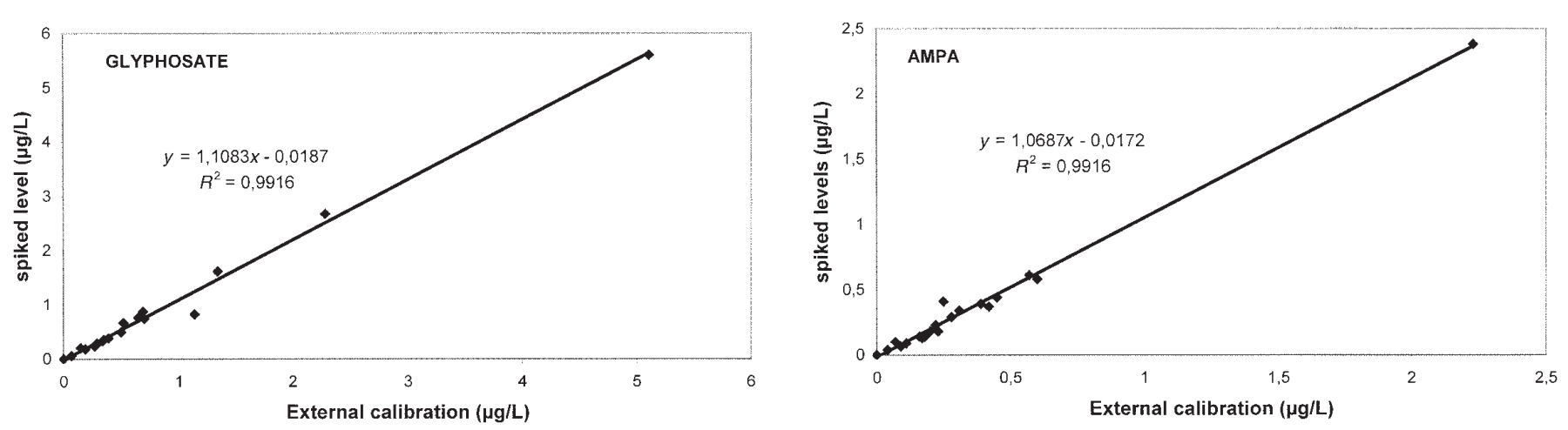

Figure 3. Correlation between external calibration and spiked levels methods for the analysis of glyphosate (a) and AMPA (b). Conditions: Macherey \& Nagel $\mathrm{NH}_{2}$ column, mobile phase 2, procedure 3 of sample preparation.

This optimisation of sample preparation led to procedure 3. The optimum wavelengths for fluorescence were verified for the two compounds to be 260 and $310 \mathrm{~nm}$ in the mobile phase used.

The validation of procedure 3 was carried out on pure water in accordance with the experimental standard NF XP T90-210. The results are presented in table V. The sensitivity of AMPA was twice that of glyphosate with limits of detection and quantification calculated at 0.01 and $0.04 \mu \mathrm{g} / \mathrm{L}$ respectively.

\section{External calibration}

The ability of using external standard calibration was valued by the comparison with spiked levels method for 20 natural water samples (Fig. 3). The pictures clearly show a good match between the two methods. The fitting between the two methods was studied by statistical evaluation. A Student test showed that the slope was not significantly different from 1 . A second Student test showed that the origin Y-axis was not significantly different from zero. So the equivalence of the two calibration ways was proved.

\section{Conclusion}

Our laboratory possesses a validated and largely tested analytical method for glyphosate and AMPA determination in water at $0.10 \mu \mathrm{g} / \mathrm{L}$ level. This method doesn't need any extraction or purification step. The use of spiked levels and two washing steps allows us to be ensured about false positive or negative samples. However, for most natural waters, the use of external calibration is possible.

\section{References}

1. Zhu, Y.; Zhang, F.; Tong, C.; Liu, W. J. Chromatogr. A 1999, $850,297-301$.

2. Bauer, K.H.; Knepper, T.P.; Maes, A.; Schatz, V;. Voihsel, M. J. Chromatogr. A 1999, 837, 117-128.

3. Vreeken, R.J.; Speksnijder, P.; Bobeldijk-Pastorova, I.; Noij, T.H.M. J. Chromatogr. A 1998, 794, 187-199.

4. Mallat, E.; Barcelo, D. J. Chromatogr. A 1998, 823, 129-136.

5. Sundaram, K.M.S.; Curry, J. J. Liq. Chrom. \& Rel. Technol. 1997, 20, 511-524. 


\section{Original articles}

6. Parrot, F.; Bedry, R.; Favarel-Garrigues, J.C. Clinical Toxicology 1995, 33, 695-698.

7. Thompson, D.G.; Cowell, J.E.; Daniels, R.J.; Staznik, B.; MacDonald, L.M. J. Assoc. Off. Anal. Chem. 1989, 72, 355360 .

8. Lovdahl, M.J.; Pietrzyk, D.J. J. Chromatogr. A 1992, 602, 197 204.

9. Sancho, J.V.; Hernandez, F.; Lopez, F.J.; Hogendoorn, E.A.; Dijkman, E.; van Zoonen, P. J. Chromatogr. A 1996, 737, 7583.

10. Avramova, Y.B.; Vasilev, K.R. J. Anal. Chem. 1992, 47, 290292.

11. Kawai, S.; Uno, B.; Tomita, M. J. Chromatogr. A 1991, 450, 411-415.
12. Tomita, M.; Okuyama, T.; Watanabe, S.; Uno, B.; Kawai, S. J. Chromatogr. A 1991, 566, 239-243.

13. Powell, H.A.; Kerby, N.W.: Rowell, P. J. Chromatogr. A 1990, 502, 201-207.

14. Gauch, R.; Leuenberger, U.; Muller, U. Z. Lebensm Unters Forsch 1989, 188, 36-38.

15. Glass, R.L. J. Agric. Food Chem. 1983, 31, 280-282.

16. Roseboom, H.; Berkhoff, C.J. Analytica Chemica Acta 1982, 135, 373-377.

17. Miles, C.J.; Wallace, L.R.; Moye, H.A. J. Assoc. Off. Anal.Chem. 1986, 69, 458-461.

18. Miyano, H.; Toyo'oka, T.; Imai, K.; Nakajima, T. Analytical Biochem. 1985, 150, 125-130. 